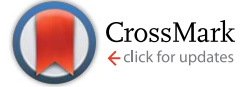

Cite this: RSC Adv., 2017, 7, 10433

Received 19th November 2016 Accepted 2nd February 2017

DOI: $10.1039 / \mathrm{c} 6 \mathrm{ra} 27036 \mathrm{k}$

rsc.li/rsc-advances

\section{Sustainable oleic and stearic acid based biodegradable surfactants $\uparrow$}

\author{
Avinash Bhadani, ${ }^{\text {a }}$ Kazuki Iwabata, ${ }^{a}$ Kenichi Sakai, ${ }^{a}$ Setsuko Koura, ${ }^{\text {b }}$ Hideki Sakai ${ }^{\text {a }}$ \\ and Masahiko Abe*a
}

Renewable ester functionalized oleic and stearic acid based imidazolium surfactants were synthesized and characterized using spectroscopic techniques. The new surfactants were investigated for their selfaggregation properties and biodegradability in aqueous solution. These fatty acid based surfactants were able to self-aggregate into micelles at lower concentration compared to conventional surfactants and were found to be readily biodegradable. The surface properties and biodegradation rate of these new renewable surfactants depend on the nature of the hydrophobic tail. The oleic acid based surfactant containing a double bond in the hydrophobic oleyl tail demonstrated a greater capability to reduce the surface tension of an aqueous solution along with a greater ability to undergo biodegradation compared to the saturated hydrophobic stearyl tail containing a stearic acid based surfactant.

\section{Introduction}

The use of surfactants in various consumer and industrial application areas continues to increase with an annual growth rate of $3-4 \%$, and petrochemical-based surfactants are still a popular choice for the bulk of application areas because of their low cost, ease of manufacturing and superior physicochemical properties. ${ }^{1}$ However, the ever-increasing demand for surfactants necessitates the development of a new generation of surfactant molecules having a considerable portion of renewable structural motifs. ${ }^{2-5}$ These new surfactants need to be developed using a sustainable approach and should contain biocompatible functional groups capable of undergoing biodegradation after use. ${ }^{6,7}$ Using renewable raw feedstock such as oleo-chemicals, ${ }^{8,9}$ carbohydrates, ${ }^{10,11}$ amino acids $^{12,13}$ etc. derived from natural sources for manufacturing surfactants will check the environmental issues since these surfactants after degradation will only release back corresponding carbon to environment, which has been previously consumed by plant for making feedstock. ${ }^{2}$

In last decade the sustainable surfactants based on renewable feedstock have attracted personal care and home care product manufacturers because of increased consumer demand for sustainable products along with growing awareness of the environmental issues. ${ }^{\mathbf{1 4 , 1 5}}$ The use of renewable feedstock for

${ }^{a}$ Department of Pure and Applied Chemistry and Research Institute for Science and Technology, Tokyo University of Science, 2641 Yamazaki, Noda, Chiba 278-8510, Japan.E-mail: abhadani@rs.tus.ac.jp; abemasa@rs.noda.tus.ac.jp

${ }^{b}$ Department of Applied Chemistry, Chiba Institute of Technology, 2-17-1, Tsudanuma, Narashino, Chiba, 275-8588, Japan

† Electronic supplementary information (ESI) available: Characterization data, ${ }^{1} \mathrm{H}$ NMR and ${ }^{13} \mathrm{C}$ NMR spectra of the compounds. See DOI: $10.1039 / \mathrm{c} 6 \mathrm{ra} 27036 \mathrm{k}$ manufacturing surfactants has witnessed reasonable growth in past decade and the market share of bio-based surfactants continues to increase with each passing year. ${ }^{\mathbf{1 6}}$ However, in order to replace commercially available petrochemical based surfactants from industrial and consumer products we need to address several concerns associated with practical application of renewable surfactants regarding their ease of manufacturing, economics, and technical and environmental performances. Surfactants directly derived from natural fatty acids can be good alternative to synthetic surfactants because of their ease of manufacturing, superior physicochemical properties and biodegradability. ${ }^{17}$ In continuation with our effort to synthesize and investigate new generation of renewable surfactants ${ }^{18-20}$ here we report new cationic surfactants based on oleic and stearic acid.

\section{Materials and methods}

\subsection{Materials}

Oleic acid, stearic acid, 2-bromoethan-1-ol, 2-bromoacetic acid, $p$-toluenesulfonic acid monohydrate, 1-methyl-1H-imidazole and potassium carbonate were purchased from TCI, Tokyo, Japan. Millipore water was used in all experiments.

\subsection{Synthesis of oleic acid and stearic acid based surfactants}

2-Bromoethan-1-ol (12.50 g, $0.1 \mathrm{~mol})$ and 2-bromoacetic acid $(13.90 \mathrm{~g}, 0.1 \mathrm{~mol})$ are reacted in the presence of catalytic amount of $p$-toluene sulphonic acid monohydrate $(1.52 \mathrm{~g}, 8 \mathrm{mmol})$ under solvent free condition for 8 hours at $85-90{ }^{\circ} \mathrm{C}$. The reaction mixture was then allowed to cool at room temperature and then washed twice with $100 \mathrm{ml}$ of water and then $100 \mathrm{ml}$ of aqueous methanol (water: methanol $=9: 1$ ) to remove 
unreacted 2-bromoethan-1-ol, 2-bromoacetic acid, catalyst and to obtain an organic layer. The organic layer was then dissolved in $100 \mathrm{ml}$ chloroform, dried using $\mathrm{Na}_{2} \mathrm{SO}_{4}$, filtered and the solvent chloroform was removed in vacuum rotary flash evaporator at $60{ }^{\circ} \mathrm{C}$ to obtain 2-bromoethyl 2-bromoacetate $(15.60 \mathrm{~g}$, $63.4 \%$ isolated yield). Further, oleic acid (7.06 g, $25 \mathrm{mmol}$ ) was reacted with 2-bromoethyl 2-bromoacetate (6.15 g, $25 \mathrm{mmol})$ and anhydrous $\mathrm{K}_{2} \mathrm{CO}_{3}(7.26 \mathrm{~g}, 52.5 \mathrm{mmol})$ in dry acetone (100 $\mathrm{ml})$ under reflux condition for 15 hours. Similarly stearic acid (7.11 g, $25 \mathrm{mmol}$ ) was reacted with 2-bromoethyl 2-bromoacetate $(6.15 \mathrm{~g}, 25 \mathrm{mmol})$ under similar conditions. The reaction mixture was allowed to cool, filtered and solvent was removed using vacuum rotary flash evaporator. The reaction mixture after removal of solvent was dissolved in $100 \mathrm{ml}$ hexane and washed twice with $100 \mathrm{ml}$ water followed by $100 \mathrm{ml}$ aqueous methanol $(1: 1)$ to get 2-(2-bromoethoxy)-2-oxoethyl oleate (9.20 g, 82.2\% isolated yield) and 2-(2-bromoethoxy)-2-oxoethyl stearate $(9.40 \mathrm{~g}, 83.4 \%$ isolated yield $)$ respectively. 2-(2Bromoethoxy)-2-oxoethyl oleate $(4.47 \mathrm{~g}, 10 \mathrm{mmol})$ was quaternized with 1-methyl-1H-imidazole $(0.82 \mathrm{~g}, 10 \mathrm{mmol})$ in $10 \mathrm{ml}$ toluene at $95{ }^{\circ} \mathrm{C}$ for 15 hours. Similarly, 2-(2-bromoethoxy)-2oxoethyl stearate $(4.49 \mathrm{~g}, 10 \mathrm{mmol})$ was quaternized with 1methyl- $1 H$-imidazole $(0.82 \mathrm{~g}, 10 \mathrm{mmol})$ under similar conditions. The reaction mixture was allowed to cool and then solvent toluene was removed using vacuum rotary flash evaporator. The crude reaction mixture was sonicated in hexane $(30 \mathrm{ml})$ for 5 minutes and the solvent was removed by filtration. The process was repeated twice to remove all unreacted components and impurities and then subsequently dried using vacuum rotary flash evaporator to get oleic acid based imidazolium surfactant: 1-methyl-3-(2-(2-(oleoyloxy)acetoxy)ethyl)-1 $H$-imidazol-3-ium bromide (Oleic Surf) and stearic acid based imidazolium surfactants: 1-methyl-3-(2-(2-(stearoyloxy)acetoxy)ethyl)-1Himidazol-3-ium bromide (Stearic Surf) in $65.1 \%$ and $70.4 \%$ isolated yield respectively.

1-Methyl-3-(2-(2-(oleoyloxy)acetoxy)ethyl)-1H-imidazol-3-ium bromide (Oleic Surf). White hygroscopic solid, yield $65.1 \% .{ }^{1} \mathrm{H}$ NMR (500 MHz, $\left.\mathrm{CDCl}_{3}\right) 10.15\left(\mathrm{~s}, 1 \mathrm{H}, \mathrm{N}^{+} \mathrm{CHN}\right), 7.78(\mathrm{~s}, 1 \mathrm{H}$, $\left.\mathrm{N}^{+} \mathrm{CHC}\right), 7.50(\mathrm{~s}, 1 \mathrm{H}, \mathrm{NCHC}), 5.34(\mathrm{~m}, 2 \mathrm{H}, \mathrm{CH}=\mathrm{CH}), 4.82(\mathrm{~m}$, $\left.2 \mathrm{H}, \mathrm{N}^{+} \mathrm{CH}_{2}\right), 4.66-4.63\left(\mathrm{~m}, 4 \mathrm{H}, \mathrm{COOCH}_{2} \mathrm{COO}, \mathrm{COOCH}_{2}\right), 4.10(\mathrm{~s}$, $\left.3 \mathrm{H}, \mathrm{NCH}_{3}\right), 2.39$ (t, $\left.J=7.6,2 \mathrm{H}, \mathrm{CH}_{2} \mathrm{COO}\right), 2.01$ (d, $J=5.30,4 \mathrm{H}$, $\left.\mathrm{CH}_{2} \mathrm{CH}=\mathrm{CHCH}_{2}\right), 1.62\left(\mathrm{~m}, 2 \mathrm{H}, \mathrm{CH}_{2} \mathrm{CH}_{2} \mathrm{COO}\right), 1.30-1.26(\mathrm{~m}$, $\left.20 \mathrm{H}, 10 \times \mathrm{CH}_{2}\right), 0.88\left(\mathrm{t}, J=6.9,3 \mathrm{H}, \mathrm{CH}_{3}\right) .{ }^{13} \mathrm{C} \mathrm{NMR}(126 \mathrm{MHz}$, $\left.\mathrm{CDCl}_{3}\right)$ 172.90, 167.17, 136.99, 129.49, 129.17, 123.13, 122.76, $62.69,60.36,48.30,36.36,33.22,31.38,29.24,29.19,29.00$, $28.79,28.67,28.61,28.52,26.70,26.66,24.27,22.17,13.64$. ESI HRMS (positive ions) calculated $m / z: 449.3374$ for $[\mathrm{M}-\mathrm{Br}]^{+}$, found 449.3379 for $[\mathrm{M}-\mathrm{Br}]^{+}$. Elemental analysis: calcd (\%) for $\mathrm{C}_{26} \mathrm{H}_{45} \mathrm{BrN}_{2} \mathrm{O}_{4}$ : C, 58.97; H, 8.57; N, 5.29; found: C, 58.84; H, 8.49; N, 5.35 .

1-Methyl-3-(2-(2-(stearoyloxy)acetoxy)ethyl)-1H-imidazol-3ium bromide (Stearic Surf). White solid, yield 70.4\%. ${ }^{1} \mathrm{H}$ NMR $\left(500 \mathrm{MHz}, \mathrm{CDCl}_{3}\right) 10.37\left(\mathrm{~s}, 1 \mathrm{H}, \mathrm{N}^{+} \mathrm{CHN}\right), 7.66\left(\mathrm{~s}, 1 \mathrm{H}, \mathrm{N}^{+} \mathrm{CHC}\right)$, $7.36(\mathrm{~s}, 1 \mathrm{H}, \mathrm{NCHC}), 4.83\left(\mathrm{~m}, 2 \mathrm{H}, \mathrm{N}^{+} \mathrm{CH}_{2}\right), 4.66-4.63(\mathrm{~m}, 4 \mathrm{H}$, $\left.\mathrm{COOCH}_{2} \mathrm{COO}, \mathrm{COOCH}_{2}\right), 4.09\left(\mathrm{~s}, 3 \mathrm{H}, \mathrm{NCH}_{3}\right), 2.39(\mathrm{t}, J=7.6,2 \mathrm{H}$, $\mathrm{CH}_{2} \mathrm{COO}$ ), 1.62 (m, 2H, $\left.\mathrm{CH}_{2} \mathrm{CH}_{2} \mathrm{COO}\right), 1.30-1.26(\mathrm{~m}, 28 \mathrm{H}, 10 \times$ $\left.\mathrm{CH}_{2}\right), 0.88\left(\mathrm{t}, \mathrm{J}=6.9,3 \mathrm{H}, \mathrm{CH}_{3}\right) \cdot{ }^{13} \mathrm{C} \mathrm{NMR}\left(126 \mathrm{MHz}, \mathrm{CDCl}_{3}\right)$
$173.24,167.41,137.41,123.23,123.03,62.90,60.61,48.59$, $36.61,33.48,31.67,29.46$, 29.25, 29.12, 29.03, 28.82, 24.55, 22.44, 13.89. ESI HRMS (positive ions) calculated $\mathrm{m} / \mathrm{z}: 451.3530$ for $[\mathrm{M}-\mathrm{Br}]^{+}$, found 451.3535 for $[\mathrm{M}-\mathrm{Br}]^{+}$. Elemental analysis: calcd (\%) for $\mathrm{C}_{26} \mathrm{H}_{47} \mathrm{BrN}_{2} \mathrm{O}_{4}: \mathrm{C}, 58.75 ; \mathrm{H}, 8.91 ; \mathrm{N}, 5.27$; found: $\mathrm{C}$, 58.89; H, 8.99; N, 5.36.

\subsection{Conductivity measurements}

Conductivity was measured using an auto-temperature electrical conductivity meter CM-25R (DKK-TOA Corporation) equipped with a conductivity cell having a cell constant of 1 . The solutions were thermostated at 25.0, 30.0, 35.0 and $40.0{ }^{\circ} \mathrm{C}$ in a thermostated glass vessel controlled by temperature controller. For the determination of critical micelle concentration (cmc) adequate quantity of a concentrated surfactant solution was added to water in order to change the surfactant concentration from concentrations well below the cmc to up to at least $2-3$ times the cmc. Degree of counterion binding $(\beta)$ is calculated from the slope of conductivity data before and after $\mathrm{cmc}$ values. The ratio of slopes after and before the $\mathrm{cmc}$ values

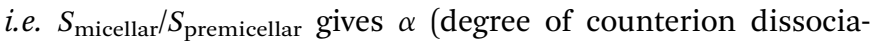
tion) and $(1-\alpha)$ gives $\beta$ value. ${ }^{21,22}$

\subsection{Surface tension measurements}

The surface tension at water-air interface was investigated using KRÜSS K100 tensiometer (KRÜSS, Germany) by Wilhelmy plate at $25{ }^{\circ} \mathrm{C}$. The tensiometer was calibrated using Millipore water. Experimental runs chosen are based on time required for the surfactant solution to attain equilibrium and hence set of ten consecutive readings with standard deviation less than 0.1 $\mathrm{mN} \mathrm{m}^{-1}$ was taken into account. The surface parameters i.e. surface excess concentration $\left(\Gamma_{\mathrm{cmc}}\right)$, surface area occupied by molecule at air/water interface $\left(A_{\min }\right)$, the effectiveness of surface tension reduction $\left(\gamma_{\mathrm{min}}\right)$ and $\mathrm{cmc}$ were calculated from the slope of decrease in surface tension with increasing concentration of surfactant solution. As a standard procedure, individual surfactant solution of different concentration is aged for minimum 24 hours at room temperature. The surfactant solution is then transferred to temperature-controlled vessel and then magnetically stirred for 2 minutes (KRUSS K100 is fitted automatic temperature controlled stirring unit). The dilute aqueous surfactant solution is then allowed to attain $25{ }^{\circ} \mathrm{C}$. When the required temperature is attained the clean platinum plate connected to the main instrument is automatically bought down by automatic interface detection method to start the experiments. Before and after recording the surface tension readings the plate is washed each time with methanol to remove any adhering or adsorbed surfactant molecule present in the plate after experimentation (methanol is used because surfactant under investigation has high solubility in methanol). After washing with methanol the plate is washed with acetone and then dried on blue flame of alcohol burner (sprit lamp). The plate is then allowed to cool and reading for reference water (Millipore) is observed before running the experiment for another sample. ${ }^{23}$ 


\subsection{Dynamic light scattering (DLS) measurements}

The size of micelles formed by oleic acid and stearic acid based surfactants were measured with a DLS measuring apparatus (NICOMP 380 ZLS, Particle Sizing Systems) at $25.0^{\circ} \mathrm{C}$. The surfactant stock solutions were passed through polycarbonate filter with a pore size of $0.2 \mu \mathrm{m}$ and then diluted to get $0.5 \mathrm{mM}$ concentration. The samples were thermally equilibrated for $60 \mathrm{~min}$ before measurement and an average of 5 measurement runs were considered for getting the size of micelle. ${ }^{24,25}$

\subsection{Biodegradability assessment}

The biodegradability of the new oleic and stearic acid based cationic surfactants were investigated by the BOD method using activated sludge. ${ }^{26}$ Biochemical oxygen demand (BOD) of the surfactant solution was determined on BOD System 6 (VELP Scientifica, Italy) fitted with BOD sensor system screwed directly on each bottle. The BOD values were recorded after 48 hour interval for 2 weeks. The biodegradability was estimated using the following equation:

$$
\text { Biodegradability }(\%)=[(\mathrm{BOD}-\text { blank }) / \mathrm{TOD}] \times 100
$$

in which blank represents the oxygen consumption in the blank dispersion, and TOD represents the theoretical oxygen demand. ${ }^{27}$

\section{Results and discussion}

\subsection{Synthesis and characterization of oleic acid and stearic acid based cationic surfactants}

Oleic acid and stearic acid based imidazolium surfactant were synthesized in a 3-step process (Scheme 1). In the first step 2bromoethan-1-ol and 2-bromoacetic acid were esterified in presence of catalytic amount of $p$-toluene sulphonic acid monohydrate under solvent free condition to get 2-bromoethyl 2bromoacetate. In the second step oleic acid and stearic acid were reacted with 2-bromoethyl 2-bromoacetate synthesized in the first step to get 2-(2-bromoethoxy)-2-oxoethyl oleate and 2-(2bromoethoxy)-2-oxoethyl stearate respectively, which were further quaternized with 1-methyl-1 $H$-imidazole to get oleic acid based imidazolium surfactant - 1-methyl-3-(2-(2-(oleoyloxy) acetoxy)ethyl)- $1 H$-imidazol-3-ium bromide (Oleic Surf) and stearic acid based imidazolium surfactants - 1-methyl-3-(2-(2(stearoyloxy)acetoxy)ethyl)-1H-imidazol-3-ium bromide (Stearic Surf). The molecular structure of the new surfactants was characterized by ${ }^{1} \mathrm{H}$ and ${ }^{13} \mathrm{C}$ NMR and mass spectroscopy and the purity of these surfactants were determined by elemental analysis.

Fig. 1 shows ${ }^{1} \mathrm{H}$ NMR spectra of oleic acid and stearic acid based surfactants. The observed chemical shift for $-\mathrm{NCHN}-$ proton of the imidazolium cation is often observed downfield compared to the $-\mathrm{NCHCHN}$ - protons and has been previously explained in detail based electronic structure of the imidazolium cation. ${ }^{28}$ This characteristic signals for $-\mathrm{NCHN}$ - protons of the imidazolium cationic for the synthesized surfactants were observed downfield as singlet at $\delta 10.15$ and $10.35 \mathrm{ppm}$ for Oleic
Surf and Stearic Surf respectively. ${ }^{29,30}$ The proton signals for the other two protons of the imidazolium ring i.e. -NCHCHN-were observed between $\delta 7.36-7.78 \mathrm{ppm}$ and the methyl protons of the imidazolium moiety appeared as singlet at $\delta 4.09-4.10 \mathrm{ppm}$ for both the surfactants. The signal for methylene protons directly attached to imidazolium cation was observed at $\delta 4.82-$ $4.83 \mathrm{ppm}$. The resonance for the methylene protons in between the two ester functional groups were observed along with the methylene protons adjacent to ester functional group ( $\beta$ to imidazolium cation) at $\delta$ 4.63-4.66 ppm integrating for four protons. The chemical shift for methine protons $(-\mathrm{CH}=\mathrm{CH}-)$ of the Oleic Surf was observed at $\delta 5.34 \mathrm{ppm}$ and two methylene protons adjacent to this unsaturation were observed at $\delta 2.01 \mathrm{ppm}$.

The ${ }^{13} \mathrm{C}$ NMR further helped to establish the molecular structure of the oleic and stearic acid based surfactants. The characteristic signals for carbonyl carbon of two ester functional group were observed downfield between $\delta$ 167.17173.24 ppm for the surfactants. This signal for $-\mathrm{NCHN}-$ carbon of the imidazolium cationic were observed at $\delta 136.99$ and $137.41 \mathrm{ppm}$ for Oleic Surf and Stearic Surf respectively. The signals for the other two carbons of the imidazolium ring i.e. $-\mathrm{NCHCHN}$ - were observed between $\delta 122.76-123.23 \mathrm{ppm}$. The chemical shift for unsaturated carbon-carbon double bond $(-\mathrm{CH}=\mathrm{CH}-)$ of the Oleic Surf was observed at $\delta 129.17-$ $129.49 \mathrm{ppm}$. The chemical shift for the methylene carbon in between the two-ester functional groups was observed at $\delta$ 62.69-62.90 ppm while the signals for the carbon directly attached to the imidazolium cation was observed at $\delta 48.30$ $48.59 \mathrm{ppm}$. The structures of the oleic and stearic acid based surfactants have been further established by high-resolution mass spectroscopy (ESI-HRMS positive ion). The parent ion peak for the surfactants has been observed for positive ion minus bromide ion from each surfactant molecule. The calculated $\mathrm{m} / \mathrm{z}$ values for Oleic Surf $\left(449.3374\right.$ for $\mathbf{M}^{+}$) and Stearic Surf (451.3530 for $\mathrm{M}^{+}$) closely matched the observed values of 449.3379 for Oleic Surf and 451.3535 for Stearic Surf.

\subsection{Conductivity measurements}

The cmc of the new fatty acid based surfactants were determined by the conductivity measurements (Table 1) and its value for Oleic Surf containing one double bond in the hydrophobic oleyl tail is higher compared to the Stearic Surf containing saturated hydrophobic stearyl tail (Fig. 2). The cmc values of these new renewable ester based imidazolium surfactants are lower compared to other types of non-functionalized imidazolium surfactants (i.e. 1-alkyl-3-methyl-imidazolium chlorides, ${ }^{31,32}$ 1-alkyl-3-methyl-imidazolium bromides ${ }^{33-36}$ ) and functionalized imidazolium surfactants (i.e. hydroxy group containing imidazolium surfactants, ${ }^{37,38}$ ester based imidazolium surfactants, ${ }^{39,40}$ aryl group containing imidazolium surfactants $^{41}$ etc.).

The degree of counterion binding $(\beta)$ of the Oleic Surf and Stearic Surf is calculated from the ratio of the slopes of two linear regimes in conductivity plot. $\beta$ values of surfactants in 
(i) Synthesis of 2-Bromoethyl 2-bromoacetate

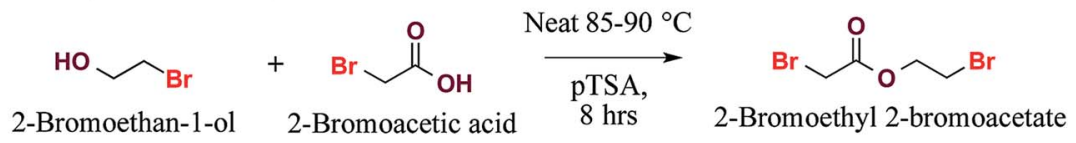

(ii) Synthesis of 2-(2-bromoethoxy)-2-oxoethyl oleate and 2-(2-bromoethoxy)-2-oxoethyl stearate

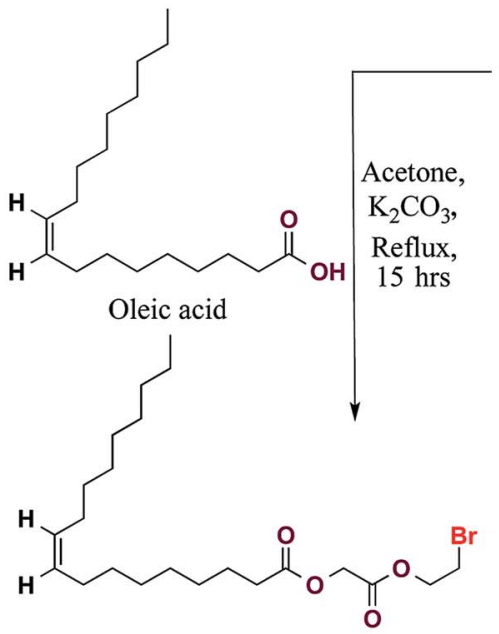

2-(2-bromoethoxy)-2-oxoethyl oleate

(iii) Quaternization step

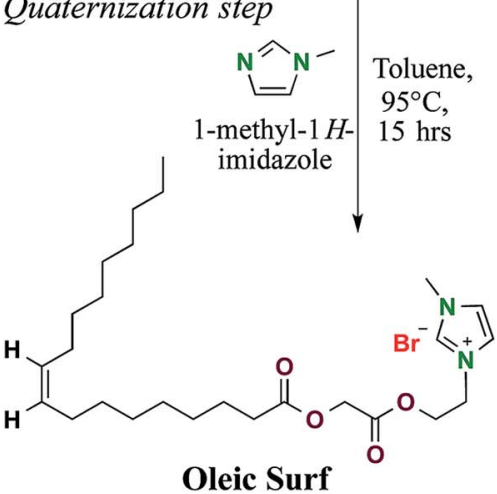

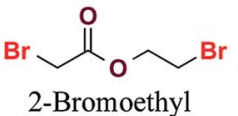

2-bromoactate<smiles>C1CCCCC1</smiles>
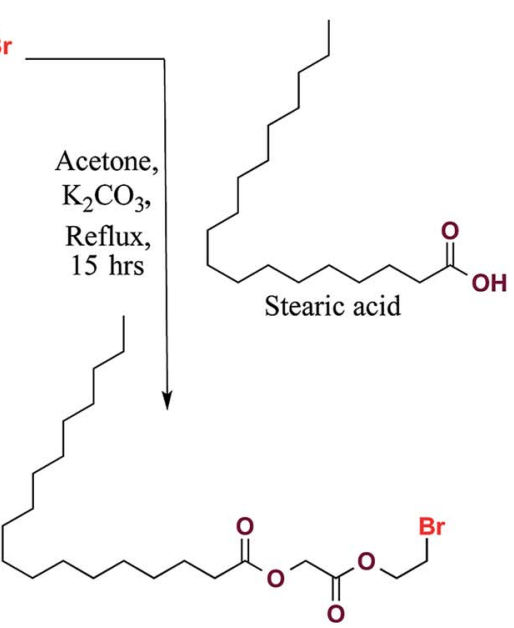

2-(2-bromoethoxy)-2-oxoethyl stearate

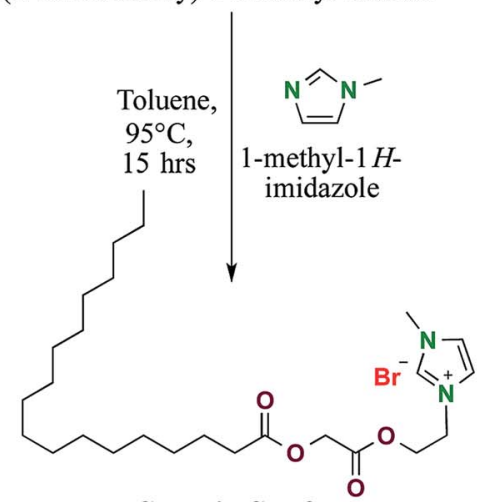

Stearic Surf

Scheme 1 Synthesis of oleic and stearic acid based cationic surfactants.

aqueous solution denote the negatively charged bromide counterion associated with the micelles and are important parameter in calculating thermodynamic parameters of the aqueous surfactant solution. The $\beta$ value for these surfactants under investigation varies with increase in temperature of surfactants solutions.

The free energy of micellization $\left(\Delta G_{\text {mic }}^{\circ}\right)$ as well as the free energy of adsorption $\left(\Delta G_{\text {ads }}^{\circ}\right)$ for the Oleic Surf and Stearic Surf has been calculated based on eqn (1) and (2). ${ }^{42}$ The $\Delta G_{\text {mic }}^{\circ}$ reflects the work done to transfer the surfactant molecules from the monomeric form at the air-water interface to the micellar phase in the bulk aqueous solution and $\Delta G_{\text {ads }}^{\circ}$ represents the energy required to transfer of $1 \mathrm{~mol}$ of surfactant in bulk solution to the air-water interface. $\Delta G_{\text {mic }}^{\circ}$ and $\Delta G_{\text {ads }}^{\circ}$ are always negative, indicating tendencies of surfactant molecules to form micelles in aqueous solution and to adsorb at the air/water interface. ${ }^{\mathbf{4 3 4 4}} \Delta G_{\text {mic }}^{\circ}$ has been calculated from following equation:

$$
\Delta G_{\mathrm{mic}}^{\circ}=(2-\beta) R T \ln X_{\mathrm{cmc}}
$$

where $R$ is the gas constant $\left(8.314 \mathrm{~J} \mathrm{~mol}^{-1} \mathrm{~K}^{-1}\right)$; $T$ is absolute temperature; $X_{\mathrm{cmc}}$ is the cmc in molar fraction, $X_{\mathrm{cmc}}=\mathrm{cmc} / 55.4$, where $\mathrm{cmc}$ is in $\mathrm{mol} \mathrm{L}^{-1}$, and 55.4 comes from $1 \mathrm{l}$ of water corresponding to $55.4 \mathrm{~mol}$ of water. $\beta$ is the degree of counterion binding to micelles. ${ }^{42}$ The $\Delta G_{\text {ads }}^{\circ}$ is calculated by the following equation:

$$
\Delta G_{\mathrm{ads}}^{\circ}=\Delta G_{\mathrm{mic}}^{\circ}-\frac{\pi_{\mathrm{cmc}}}{\Gamma}
$$

here, $\pi_{\mathrm{cmc}}$ denotes the surface pressure at the cmc, $\pi_{\mathrm{cmc}}=\gamma_{\mathrm{o}}-$ $\gamma_{\mathrm{cmc}}$, where $\gamma_{\mathrm{o}}$ and $\gamma_{\mathrm{cmc}}$ are the surface tensions of water and the surfactant solution at cmc, respectively and $\Gamma$ is the maximum surface excess concentration at the air/water interface (both determined from surface tension experiments).

The $\Delta G_{\text {mic }}^{\circ}$ values for the Oleic Surf and Stearic Surf are negative which indicates that micellization is a spontaneous process and since its absolute values increase with increase in 


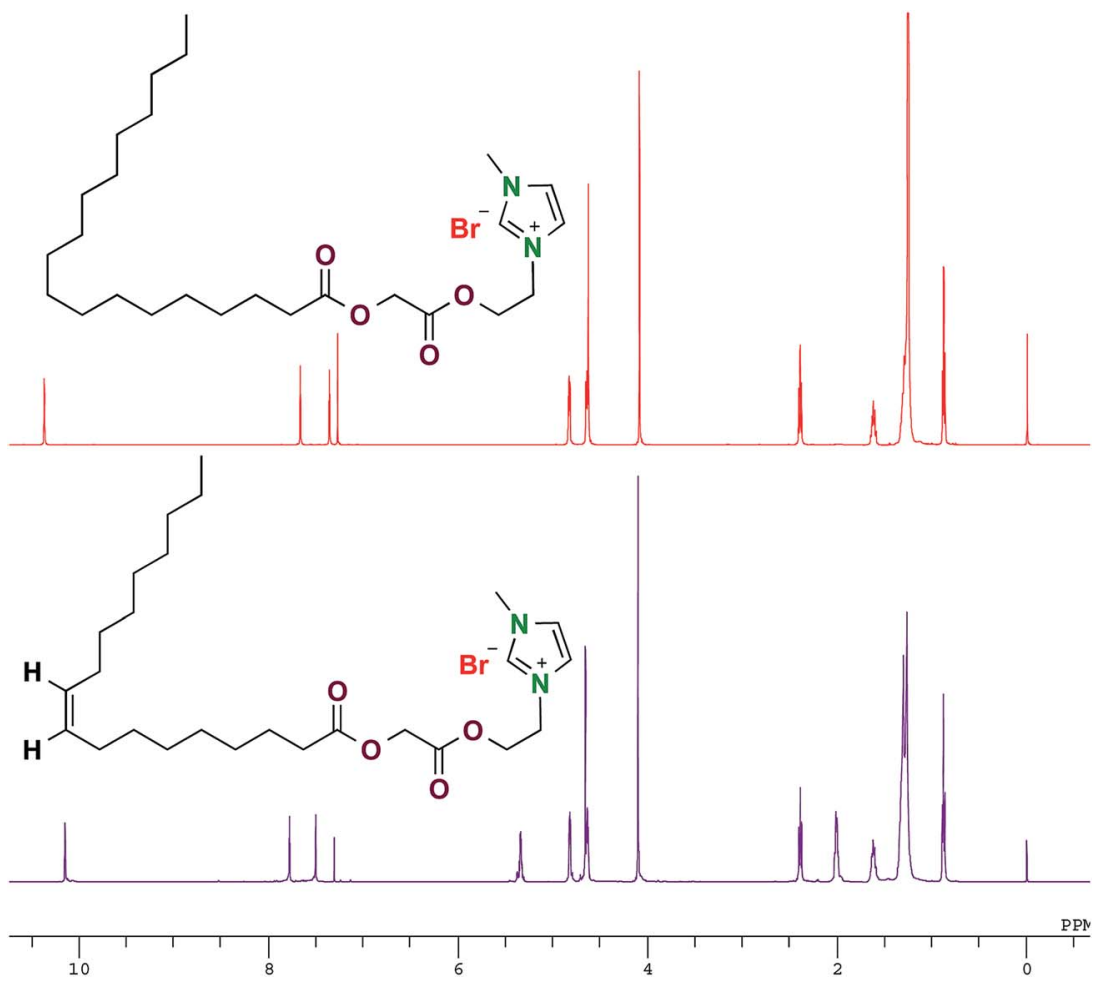

Fig. $1{ }^{1} \mathrm{H}$ NMR spectra of oleic acid and stearic acid based surfactants.

temperature, the micelle formation is favored at higher temperature. The results also indicate that the micellization process is favored at higher temperature for Stearic Surf having saturated stearyl hydrophobic tail since the calculated $\Delta G_{\text {mic }}^{\circ}$ absolute values for Oleic Surf having unsaturation in its tail length is comparatively lower at elevated temperature. The calculated absolute value of $\Delta G_{\text {ads }}^{\circ}$ for Oleic Surf is higher compared to Stearic Surf indicating that the adsorption at the air-water interface is more favorable for oleic acid based surfactant containing one unsaturated double bond in hydrophobic alkyl tail.

When the aqueous dilute surfactant solution of these surfactant were evaluated for their ability to reduce surface tension of aqueous solution by surface tension experiments (discussed later), Oleic Surf unusually took longer time to attain equilibrium surface tension value compared to stearic acid based surfactant Stearic Surf. This unusual behavior can be explained on the basis of energy difference between the $\Delta G_{\text {mic }}^{\circ}$ and $\Delta G_{\text {ads }}^{\circ}$ of the two surfactants. The absolute $\Delta G_{\text {ads }}^{\circ}$ values for both the surfactants are greater than the $\Delta G_{\text {mic }}^{\circ}$ values indicating that the adsorption of surfactant monomers at air-water interface is preferred over micellization. However when the airwater interface is completely occupied by the surfactant monomers, they start to form micelle in aqueous solution. The free energy gap between $\Delta G_{\text {mic }}^{\circ}$ and $\Delta G_{\text {ads }}^{\circ}$ for Oleic Surf is much greater than that for Stearic Surf. The difference in energy gap between the two can be attributed to the presence/absence of double bond in hydrophobic tail. The Stearic Surf containing saturated stearyl hydrophobic tail is able to readily undergo micellization as the absolute energy gap between $\Delta G_{\text {mic }}^{\circ}$ and $\Delta G_{\text {ads }}^{\circ}$ is lower compared to Oleic Surf. Greater is the energy difference between the $\Delta G_{\text {mic }}^{\circ}$ and $\Delta G_{\text {ads }}^{\circ}$, slower is the

Table 1 The surface parameters of Oleic Surf and Stearic Surf at different temperatures

\begin{tabular}{lllll}
\hline Surfactant & $T\left({ }^{\circ} \mathrm{C}\right)$ & $\mathrm{cmc}\left(\mathrm{mmol} \mathrm{l}^{-1}\right)$ & $\beta(\%)$ & $\Delta G_{\mathrm{mic}}^{\circ}\left(\mathrm{kJ} \mathrm{mol}^{-1}\right)$ \\
\hline Oleic Surf & $25 \pm 0.1$ & 0.142 & 44.6 & -49.59 \\
& $30 \pm 0.1$ & 0.156 & 40.2 & -51.47 \\
& $35 \pm 0.1$ & 0.170 & 37.7 & -52.78 \\
Stearic Surf & $40 \pm 0.1$ & 0.184 & 36.9 & -53.57 \\
& $25 \pm 0.1$ & 0.052 & 57.6 & -48.99 \\
& $30 \pm 0.1$ & 0.058 & 38.8 & -55.94 \\
& $35 \pm 0.1$ & 0.066 & 29.9 & -59.44 \\
ads & $\left(\mathrm{kJ} \mathrm{mol}^{-1}\right)$ \\
& $40 \pm 0.1$ & 0.072 & 34.1 & -58.54
\end{tabular}



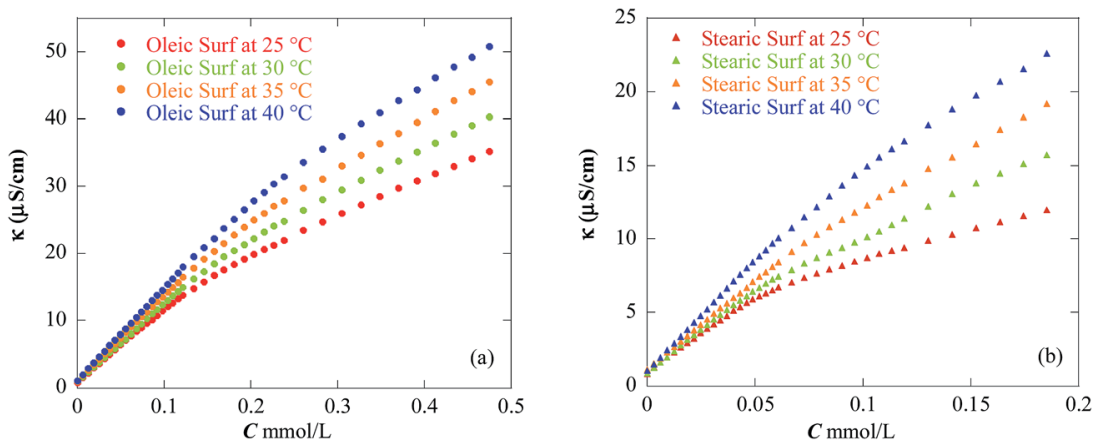

Fig. 2 Specific conductivity $(\kappa)$ versus the concentration of (a) oleic and (b) stearic acid based surfactants at different temperatures.

micellization process and hence Oleic Surf takes longer time to attain equilibrium surface tension value compared to Stearic Surf. ${ }^{45}$

\subsection{Surface tension measurements}

The surfactant properties of Oleic Surf and Stearic Surf were also investigated by surface tension measurements using plate method. Fig. 3 shows decrease in surface tension versus log of concentration plot for both the surfactants under investigation.

The cmc values determined by surface tension experiments were about one order of magnitude lower compared to those determined by the conductivity experiments for both Oleic Surf and Stearic Surf. The cmc value determined for a surfactant by different techniques may vary and such behavior are often attributed to formation of non surface-active premicellar aggregates or other closely related phenomenon. ${ }^{46,47}$

The maximum surface excess concentration at the air/water interface, $\Gamma_{\max }$ is calculated by applying the Gibbs adsorption isotherm equation. ${ }^{48}$

$$
\Gamma_{\mathrm{mac}}=-\frac{1}{2.303 n R T}\left(\frac{\mathrm{d} \gamma}{\mathrm{d} \log C}\right)_{T}
$$

here, $\gamma$ denotes the surface tension, $R$ is the gas constant, $T$ is the absolute temperature, and $C$ is the surfactant concentration. The value of $n$ is taken as 2 . The area occupied per

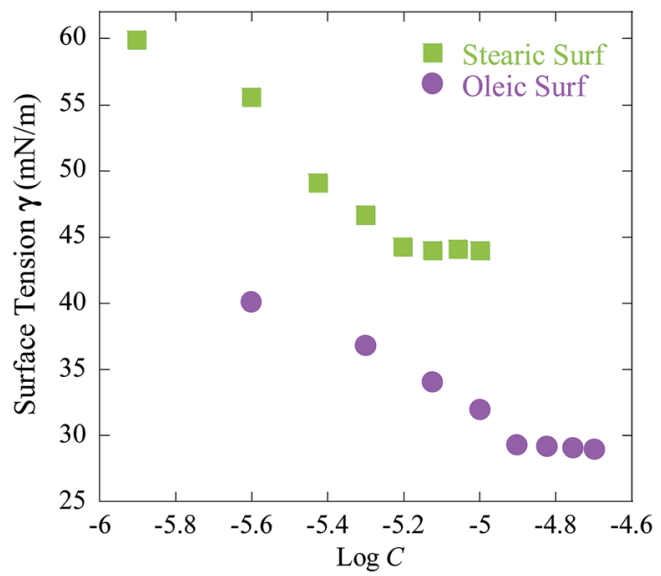

Fig. 3 Decrease in surface tension versus log of concentration plot for Oleic Surf and Stearic Surf at $25^{\circ} \mathrm{C}$. surfactant molecule $\left(A_{\min }\right)$ at air water interface is obtained by using the following equation:

$$
A_{\min }=1 / N \Gamma_{\max }
$$

where $N$ is Avogadro's number and $A_{\min }$ is in $\mathrm{nm}^{2}$. The calculated values of $\Gamma_{\max }$ and $A_{\min }$ for Oleic Surf and Stearic Surf are shown in Table 2. The $A_{\min }$ value of Oleic Surf is greater than the Stearic Surf indicating that the later forms tighter packing at air-water interface.

The maximum affinity to reduce surface tension of aqueous solution is denoted by $\gamma_{\mathrm{cmc}}$ value, which has been found to be lower for Oleic Surf (Table 2). However the observed $\gamma_{\mathrm{cmc}}$ value of Oleic Surf is much lower compared to Stearic Surf. This can be explained on the basis of conformational changes occurring at air-water interface due to cation- $\pi$ interaction between the carbon-carbon double bond $\left(-\mathrm{CH}_{\mathrm{C}} \mathrm{CH}^{-}\right)$of oleyl tail and imidazolium cation. Such intermolecular interaction at the airwater interface is responsible for the formation of network of closely associated imidazolium headgroups interacting with the double bond of oleyl hydrocarbon tail which eventually results in compensation of positive charge on imidazolium cation along with the formation of randomly oriented hydrocarbon tail at the interface. The additional intermolecular force (cation- $\pi$ interaction) operating at the air-water interface may be responsible for lower $\gamma_{\mathrm{cmc}}$ value of Oleic Surf compared to Stearic Surf. This hypothesis is supported by the fact that the imidazolium protons of Stearic Surf are observed downfield compared to imidazolium protons of Oleic Surf in $\mathrm{D}_{2} \mathrm{O}$ (Fig. 4a). Since the imidazolium protons of Oleic Surf are able to interact with the $\pi$ electrons of the oleyl tail, the proton signals of the imidazolium headgroup are observed upfield, however in the absence of double bond in Stearic Surf the imidazolium protons are strongly deshielded and often observed downfield.

Table 2 The surface properties of Oleic Surf and Stearic Surf determined by the surface tension measurement at $25^{\circ} \mathrm{C}$

\begin{tabular}{lllll}
\hline Surfactant & $\begin{array}{l}\mathrm{cmc} \\
\left(\mathrm{mmol} \mathrm{l}^{-1}\right)\end{array}$ & $\begin{array}{l}\gamma_{\mathrm{cmc}} \\
\left.(\mathrm{mN} \mathrm{m})^{-1}\right)\end{array}$ & $\begin{array}{l}10^{6} \Gamma_{\max } \\
\left(\mathrm{mol} \mathrm{m}^{-2}\right)\end{array}$ & $A_{\min }\left(\mathrm{nm}^{2}\right)$ \\
\hline Oleic Surf & 0.0127 & 29.3 & 1.31 & 1.26 \\
Stearic Surf & 0.0063 & 44.2 & 2.02 & 0.82
\end{tabular}


(a)

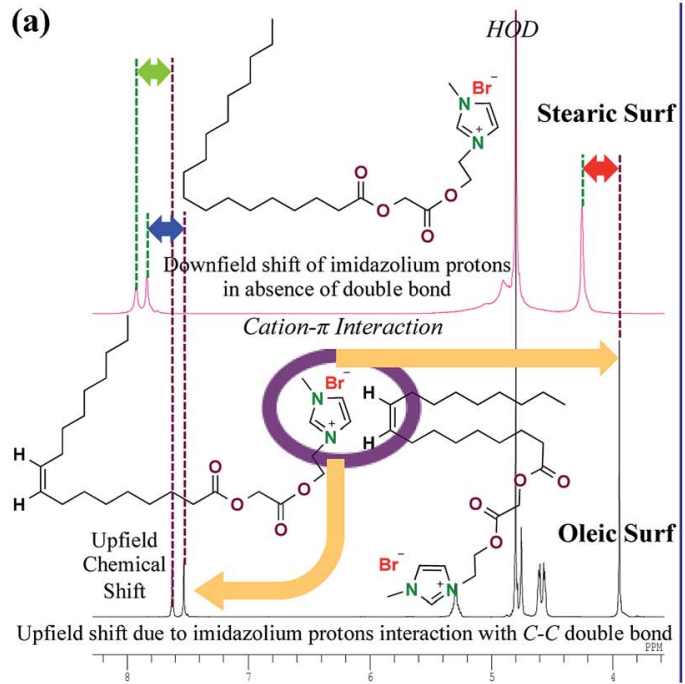

(b) Higher $A_{\min }$ value due to loose packing of monomers at interface.

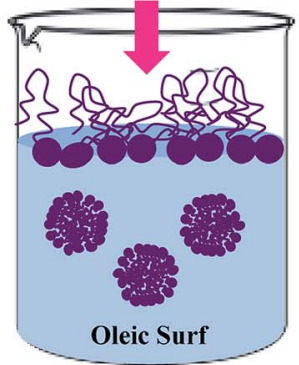

Intermolecular interaction between imidazolium cation and $C-C$ double bond of oleyl tail results in conformational changes at the interface as well as in bulk solution.
Lower $A_{\min }$ value due to compact packing of monomers at interface.

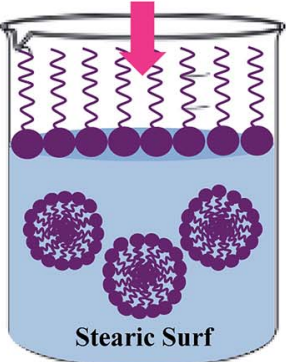

Formation of an oriented surfactant monolayer at air-water interface. The saturated stearyl tails forms compact packing at interface and assemble in bulk to form micelles.

Fig. 4 (a) ${ }^{1} \mathrm{H}$ NMR spectra of Oleic Surf and Stearic Surf in $\mathrm{D}_{2} \mathrm{O}$ demonstrating different chemical shifts of imidazolium protons. (b) Graphical representation of molecular arrangement of surfactant monomers at air-water interfaces and in bulk aqueous solution for Oleic Surf and Stearic Surf.

For Oleic Surf and Stearic Surf principally four types of intermolecular forces are acting at the air-water interface. (1) Ion-dipole interaction between positively charged imidazolium headgroup and water that keeps the headgroup bound to water at air-water interface. (2) Dipole-dipole interaction between the two polar ester functional group in the surfactant molecule and water, which forms hydrogen-bonding network that keeps region close to headgroup, bonded to water at the air-water interface. (3) Electrostatic repulsion between the positively charged headgroups that keeps the surfactant headgroup apart while maintaining the close packing of monomers at the interface. (4) Hydrophobic interactions between hydrophobic tails that keep the hydrophobic tail towards air at the air-water interface. However in addition to these intermolecular forces operating at the air-water interface, monomers of Oleic Surf are also able to interact via cation $-\pi$ interactions. The positively charged imidazolium cation of Oleic Surf is able to interact with the carbon-carbon double bond of oleyl tail of adjacent monomer through cation- $\pi$ interaction. The presence of such type of non-covalent intermolecular interaction between the Oleic Surf monomers significantly affects other types of intermolecular forces acting at air-water interface and in the bulk solution. Firstly, the hydrophobic interaction between the oleyl tails are altered and hydrophobic tails do not remain specifically oriented towards air at air-water interface as in case of Stearic Surf (Fig. 4b). The oleyl tails probably bends to interact with imidazolium cation through its carbon-carbon double bond. Secondly, both electrostatic repulsion between headgroups and ion-dipole interaction between positively charged headgroup and water molecules gets affected since the net positive charge available on imidazolium headgroup becomes less in case of Oleic Surf. These changes in intermolecular forces not only affects the arrangement of monomers at airwater interface but also significantly influences the physicochemical properties exhibited by the surfactants and Oleic Surf is able to reduce the surface tension of water to greater extent compared to the Stearic Surf. The molecular reorientation of the Oleic Surf monomers may result in formation of randomly distributed self-assembled network at air-water interface. Contrary to this the monomers of Stearic Surf are able to form tightly packed organized surfactant monolayer where the stearyl tail are oriented towards air and the air-water interface is compactly packed forming surface saturated interfacial monolayer (Fig. 4b). Hence the $A_{\min }$ value of the Oleic Surf is larger compared to the Stearic Surf.

\subsection{Dynamic light scattering (DLS) measurements}

The hydrodynamic sizes of the Oleic Surf and Stearic Surf micelles were determined by the dynamic light scattering technique. Fig. 5 shows the size distribution of Oleic Surf and Stearic Surf micelles in aqueous solutions at each $0.50 \mathrm{mM}$ concentration.

Oleic Surf formed smaller size micelles compared to Stearic Surf in aqueous solution. The ability of the Oleic Surf to form smaller size micelle can be attributed to the ability of the hydrophobic oleyl tail to interweave and form a compact micellar core consisting of randomly oriented oleyl tails. Such arrangement offers the unsaturated portion of the oleyl tail in bended form to remain in close proximity to the positively charged imidazolium headgroup thereby making the micellar system stabilize through cation- $\pi$ interactions. In contrast the Stearic Surf forms micelles with large hydrodynamic diameter since its hydrophobic micelle core consists of stearyl tails in extended form.

\subsection{Biodegradability of surfactants}

The biodegradability of the new ester functionalized Oleic Surf and Stearic Surf have been investigated by BOD method using activated sludge in closed-bottle test. Surfactants can be 


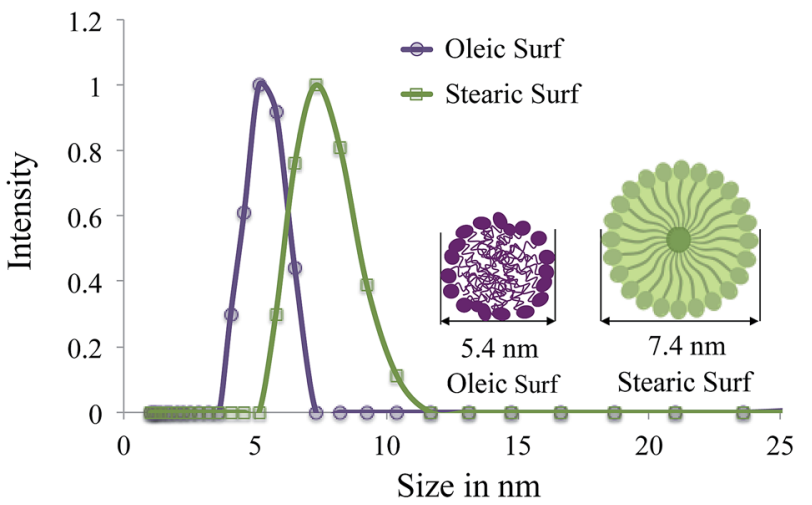

Fig. 5 Micelle size distributions of $0.50 \mathrm{mM}$ aqueous solution of Oleic Surf and Stearic Surf at $25^{\circ} \mathrm{C}$ as determined by DLS method.

classified as readily biodegradable if they are able to undergo $60 \%$ biodegradation within 28 days under aerobic conditions according to the OECD's guidelines. ${ }^{49}$

Generally incorporation of biocompatible functional groups such as ester moiety often leads to enhance biodegradation of a chemical entity including surfactants ${ }^{50,51}$ and this may be attributed to the fact that the variety of esterase enzymes present in the environment can easily biodegrade substrate molecules that contains biocompatible ester linkages. ${ }^{52}$ Several different types of cationic surfactants containing ester linkage have been previously investigated for their ability to undergo biodegradation and studies have established these categories of surfactants to be partially or readily biodegradable. ${ }^{53-55}$ Recent studies have also established ester based imidazolium surfactants to be biodegradable. ${ }^{56,57}$ Fig. 6 shows the rate of biodegradation for the Oleic Surf, Stearic Surf and a conventional standard reference cationic surfactant - benzyl- $n$-hexadecyl dimethyl ammonium chloride (BHDAC).

Both the Oleic Surf and Stearic Surf containing ester functionality have been found to be readily biodegradable under experimental condition in the presence of activated sludge, as they were able to undergo more than 60 percent structural degradation within 2 week time frame. The degradation rate of

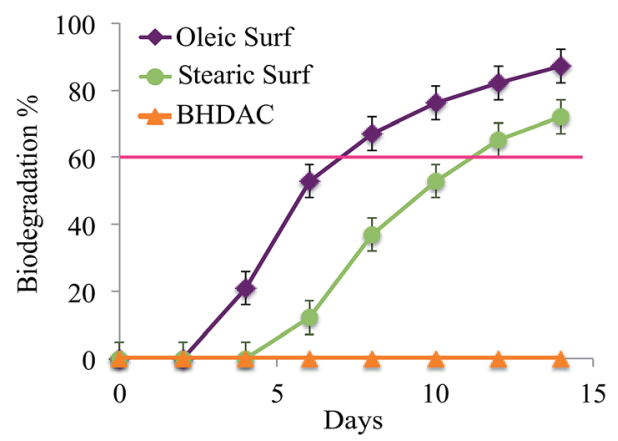

Fig. 6 Biodegradation of Oleic Surf and Stearic Surf investigated by BOD method with activated sludge. Error bars for individual data show $\pm 5 \%$ error estimates. both the cationic surfactants under investigation varied, as Oleic Surf was able to undergo rapid degradation compared to Stearic Surf. The standard benzalkonium surfactant - BHDAC was unable to degrade within 2 week time frame. However it should be noted that both the surfactants: Oleic Surf and Stearic Surf under investigation are stable in aqueous solution in the absence of activated sludge. The BOD values for the water sample containing only surfactants do not change over the experimental time period (two weeks). While it is expected that the observed BOD values of the test sample containing only surfactants dissolved in water may not show any change in absence of activated sludge even if the surfactant undergo hydrolysis in water. We examined time dependent ${ }^{1} \mathrm{H}$ NMR data for both the surfactants under investigation in $\mathrm{D}_{2} \mathrm{O}$ for 2 weeks and found that the surfactants are stable and do not undergo hydrolysis or self-degradation under the experimental time period.

\section{Conclusion}

Oleic acid and stearic acid based cationic surfactants containing imidazolium headgroup and two-ester functional groups are developed and investigated for their selfaggregation properties and biodegradability. These new surfactants have lower $\mathrm{cmc}$ values compared to conventional cationic surfactants and the surface properties of these surfactants varied depending on nature of hydrophobic fatty ester tail. Surfactant containing oleyl ester tail demonstrated greater ability to reduce surface tension of aqueous solution compared to imidazolium surfactant containing hydrophobic stearyl ester tail, however the later has lower $\mathrm{cmc}$ value compared to the former. The presence of unsaturation in hydrophobic oleyl tail significantly influences the aggregation behavior of oleic acid based surfactant both at the air-water interface as well as in the bulk aqueous solution. The stearic acid based surfactant is able to form dense packing at airwater interface. However the oleic acid based surfactant is able to interact via intermolecular cation- $\pi$ interactions thereby modifying the principle interfacial forces responsible for aggregation of monomers at air-water interface, thus resulting in loose and random packing of surfactant monomers at interface which is evident by its higher $A_{\min }$ value. The oleic acid based surfactant forms smaller size micelles compared to stearic acid based surfactant in aqueous solution. The biodegradability of both the new fatty acid based surfactants was evaluated by BOD method and both the surfactants were found to be readily biodegradable. The ease of synthesis combined with optimum surface properties and biodegradability establish these new renewable fatty acid based surfactants to be good alternative to conventional petrochemical based surfactants.

\section{Acknowledgements}

Avinash Bhadani is thankful to Tokyo University of Science and Acteiive Research and Development Company, Japan for research support. 


\section{References}

1 S. M. Mudge and P. C. Deleo, Environ. Sci.: Processes Impacts, 2014, 16, 74-80.

2 P. Foley, A. K. Pour, E. S. Beach and J. B. Zimmerman, Chem. Soc. Rev., 2012, 41, 1499-1518.

3 D. Blunk, P. Bierganns, N. Bongartz, R. Tessendorf and C. Stubenrauch, New J. Chem., 2006, 30, 1705.

4 C. Gozlan, E. Deruer, M.-C. Duclos, V. Molinier, J.-M. Aubry, A. Redl, N. Duguet and M. Lemaire, Green Chem., 2016, 18, 1994-2004.

5 C. P. Canlas and T. J. Pinnavaia, RSC Adv., 2012, 2, 7449.

6 C. Schmitt, B. Grassl, G. Lespes, J. Desbrières, V. Pellerin, S. Reynaud, J. Gigault and V. A. Hackley, Biomacromolecules, 2014, 15, 856-862.

7 K. S. Arias, M. J. Climent, A. Corma and S. Iborra, ChemSusChem, 2013, 7, 210-220.

8 Q.-Q. Zhang, B.-X. Cai, H.-Z. Gang, S.-Z. Yang and B.-Z. Mu, RSC Adv., 2014, 4, 38393.

9 K. Sakai, Y. Saito, A. Uka, W. Matsuda, Y. Takamatsu, B. Kitiyanan, T. Endo, H. Sakai and M. Abe, J. Oleo Sci., 2013, 62, 489-498.

10 R. F. Tabor, M. J. Pottage, C. J. Garvey and B. L. Wilkinson, Chem. Commun., 2015, 51, 5509-5512.

11 Y. Hu, W. Zou, V. Julita, R. Ramanathan, R. F. Tabor, R. Nixon-Luke, G. Bryant, V. Bansal and B. L. Wilkinson, Chem. Sci., 2016, 7, 6628-6634.

12 A. Pinazo, R. Pons, P. Lourdes and M. R. Infante, Ind. Eng. Chem. Res., 2011, 50, 4805-4817.

13 F. Goursaud, M. Berchel, J. Guilbot, N. Legros, L. Lemiègre, J. Marcilloux, D. Plusquellec and T. Benvegnu, Green Chem., 2008, 10, 310.

14 H. G. Hauthal, SOFW J., 2008, 134(6), 10-35.

15 P. Ruxton, Spec. Chem. Mag., 2008, 28(7), 38-39.

16 J. H. Clark, T. J. Farmer, L. Herrero-Davila and J. Sherwood, Green Chem., 2016, 18, 3914-3934.

17 R. Klein, E. Müller, B. Kraus, G. Brunner, B. Estrine, D. Touraud, J. Heilmann, M. Kellermeier and W. Kunz, RSC Adv., 2013, 3, 23347.

18 K. Sakai, Y. Sangawa, Y. Takamatsu, T. Kawai, M. Matsumoto, H. Sakai and M. Abe, J. Oleo Sci., 2010, 59, 541-548.

19 Y. Takamatsu, N. Iwata, K. Tsubone, K. Torigoe, T. Endo, K. Sakai, H. Sakai and M. Abe, J. Colloid Interface Sci., 2009, 338, 229-235.

20 K. Sakai, H. Sakai and M. Abe, J. Oleo Sci., 2011, 60, 159-163. 21 A. Bhadani, M. Tani, T. Endo, K. Sakai, M. Abe and H. Sakai, Phys. Chem. Chem. Phys., 2015, 17, 19474-19483.

22 A. Bhadani, T. Okano, T. Ogura, T. Misono, K. Sakai, M. Abe and H. Sakai, Colloids Surf., A, 2016, 494, 147-155.

23 A. Bhadani, R. G. Shrestha, S. Koura, T. Endo, K. Sakai, M. Abe and H. Sakai, Colloids Surf., A, 2014, 461, 258-266.

24 D. Minami, S. Horikoshi, K. Sakai, H. Sakai and M. Abe, J. Jpn. Soc. Colour Mater., 2011, 84, 39-42.

25 P. Bakardzhiev, S. Rangelov, B. Trzebicka, D. Momekova, G. Lalev and V. M. Garamus, RSC Adv., 2014, 4, 37208.
26 S. Gou, T. Yin, Q. Xia and Q. Guo, RSC Adv., 2015, 5, 3206432071.

27 T. Yoshimura, K. Ishihara and K. Esumi, Langmuir, 2005, 21, 10409-10415.

28 A. Bhadani, J. Rane, C. Veresmortean, S. Banerjee and G. John, Soft Matter, 2015, 11, 3076-3082.

29 A. Bhadani and S. Singh, Langmuir, 2011, 27, 14033-14044.

30 R. Kamboj, S. Singh, A. Bhadani, H. Kataria and G. Kaur, Langmuir, 2012, 28, 11969-11978.

31 C. Jungnickel, J. Łuczak, J. Ranke, J. F. Fernández, A. Müller and J. Thöming, Colloids Surf., A, 2008, 316, 278-284.

32 O. A. E. Seoud, P. A. R. Pires, T. Abdel-Moghny and E. L. Bastos, J. Colloid Interface Sci., 2007, 313, 296-304.

33 M. Blesic, M. H. Marques, N. V. Plechkova, K. R. Seddon, L. P. N. Rebelo and A. Lopes, Green Chem., 2007, 9, 481.

34 B. Dong, N. Li, L. Zheng, L. Yu and T. Inoue, Langmuir, 2007, 23, 4178-4182.

35 J. Bowers, C. P. Butts, P. J. Martin, M. C. Vergara-Gutierrez and R. K. Heenan, Langmuir, 2004, 20, 2191-2198.

36 T. Inoue, H. Ebina, B. Dong and L. Zheng, J. Colloid Interface Sci., 2007, 314, 236-241.

37 R. Kamboj, S. Singh and V. Chauhan, Colloids Surf., A, 2014, 441, 233-241.

38 V. Chauhan, S. Singh and A. Bhadani, Colloids Surf., A, 2012, 395, 1-9.

39 A. R. Tehrani-Bagha and K. Holmberg, Langmuir, 2010, 26, 9276-9282.

40 A. Tehrani-Bagha, H. Oskarsson, C. V. Ginkel and K. Holmberg, J. Colloid Interface Sci., 2007, 312, 444-452.

41 L. Shi, N. Li, H. Yan, Y. A. Gao and L. Zheng, Langmuir, 2011, 27, 1618-1625.

42 A. Bhadani, S. Singh, R. Kamboj and V. Chauhan, Colloid Polym. Sci., 2013, 291, 2289-2297.

43 A. Callaghan, R. Doyle, E. Alexander and R. Palepu, Langmuir, 1993, 9, 3422-3426.

44 W. Guoyong, D. Zhiping, L. Qiuxiao and Z. Wei, J. Phys. Chem. B, 2010, 114, 6874.

45 T. Yoshimura, M. Bong, K. Matsuoka, C. Honda and K. Endo, J. Colloid Interface Sci., 2009, 339, 230-235.

46 L. Wang, Y. Zhang, L. Ding, J. Liu, B. Zhao, Q. Deng and T. Yan, RSC Adv., 2015, 5, 74764-74773.

47 P. Quagliotto, G. Viscardi, C. Barolo, D. D'angelo, E. Barni, C. Compari, E. Duce and E. Fisicaro, J. Org. Chem., 2005, 70, 9857-9866.

48 A. Bhadani, T. Endo, S. Koura, K. Sakai, M. Abe and H. Sakai, Langmuir, 2014, 30, 9036-9044.

49 A. Tehrani-Bagha, K. Holmberg, C. V. Ginkel and M. Kean, J. Colloid Interface Sci., 2015, 449, 72-79.

50 A. Natrajan and D. Wen, RSC Adv., 2013, 3, 21398.

51 A. Jordan and N. Gathergood, Chem. Soc. Rev., 2015, 44, 8200-8237.

52 D. Coleman and N. Gathergood, Chem. Soc. Rev., 2010, 39, 600.

53 M. Akram, S. Anwar, F. Ansari, I. A. Bhat and K.-U.-D. KabirUd-Din, RSC Adv., 2016, 6, 21697-21705. 
54 A. Tehrani-Bagha, H. Oskarsson, C. V. Ginkel and K. Holmberg, J. Colloid Interface Sci., 2007, 312, 444-452.

55 A. R. Tehrani-Bagha and K. Holmberg, Langmuir, 2010, 26 9276-9282.
56 N. N. Al-Mohammed, R. S. D. Hussen, T. H. Ali, Y. Alias and Z. Abdullah, RSC Adv., 2015, 5, 21865-21876.

57 N. N. Al-Mohammed, R. S. D. Hussen, Y. Alias and Z. Abdullah, RSC Adv., 2015, 5, 2869-2881. 